\title{
Fire Safety Design for Buildings with an Atrium
}

\author{
HIROOMI SATO and TOMIO OUCHI \\ Kajima Institute of Construction Technology \\ Japan
}

HITOSHI KURIOKA

Kajima Corporation

Japan

\section{ABSTRACT}

This paper firstly explains that, with regards to the design of buildings with an atrium, due consideration should be given to smoke discharge systems from the atrium to the outside and to the performance and specifications of the atrium peripheral walls and openings. This is partly because the atrium space and the adjacent spaces differ in terms of size, usage, number of occupants and their activities. SecondIy, a method of predicting the fire behavior of an atrium, followed by applying the results in an example is introduced. In this example, the fire behavior is predicted for an atrium of $80 \mathrm{~m}$ height and 310 $\mathrm{m}^{2}$ base area. In this case it was proven that it would be fire-safe if. the following conditions were met: the conditions inside the atrium during a fire are made similar to those of the outside by means of an automatic smoke discharge opening (effective area: $20 \mathrm{~m}^{2}$ ) at the top of the atrium together with an air inlet $\left(35 \mathrm{~m}^{2}\right)$ at the lower part, and the building has atrium peripheral curtain walls of aluminum, which can resist fire for 1 hour, and an opening with a fixed window with wired-glass of $1.23 \mathrm{~m}$ maximum height on each floor.

\section{INTRODUCTION}

The design of a building varies according to type and function (social requirements) and technological development as well as the requirements of the designer and client. Thus many types of structure have been produced. Recent examples include the Shin Kokugikan (New Sumo-Arena), large-space facilities like air-dome structures, large multi-purpose buildings, and office buildings. For these structures, harmonious, large inner spaces, sometimes with greenery, are increasingly popular.

Basically, a fire prevention plan for a building should be made from an overall point of view, aiming to attain the safety target of the building by predicting what types of fires may occur in it and their possible effect on people and the building. This principle is true also for buildings with an atrium.

A special point to be considered for the fire prevention in buildings with an atrium is that spaces for various purposes are provided

Key words: atrium, fire behavior, fire prevention plan, modeling 
adjacent to a large, common, high-ceilinged space called the atrium, and that there can be many people in the peripheral spaces who have varying activities. In other words, the probability of occurrence and the size of fires, as well as the activities of people and value of assets to be protected, differ for these buildings. In addition, the smoke discharge systems from the atrium to the outside determine the flame spread route and size of a fire. The performance of the peripheral walls of an atrium is also a determining factor in the spread of a fire: if the fire resistance properties of the atrium peripheral walls and openings are insufficient, heat and smoke from the fire can easily spread. Furthermore, if the material of an opening is glass, occupants on other floors can visually be made aware of the fire and many of them will try to evacuate at the same time, which may lead to staircases being overcrowded and a possible secondary disaster. The most significant points for buildings with an atrium are thus the design of the atrium partition walls the smoke control in the atrium. If glass is used for openings or the roof, some preventive measures against falling glass are also necessary. In addition, if there are openings facing the atrium, the possibility of flames spreading to upper floors and towards the opposite space require the roof of the atrium to be able to resist fire.

This study discusses safety measures against fires including various engineering prediction methods. The example discussed is an office building which has an opening facing an atrium.

\section{OUTLINE OF THE BUTLDING AND ITEMS FOR DISCUSSION}

The office building to be studied consists of 20 stories above ground and 2 stories below. As Fig.1 shows, buildings $A$ and $B$ of the same size are joined by an atrium (height $80 \mathrm{~m}$; base area $310 \mathrm{~m}^{2}$ ). The basement of the atrium is used as a cafeteria as well as for restaurants and coffee shops. The atrium includes the main lobby on the first floor, and is enclosed by office spaces on the standard floors from the 2nd to 19 th floors.

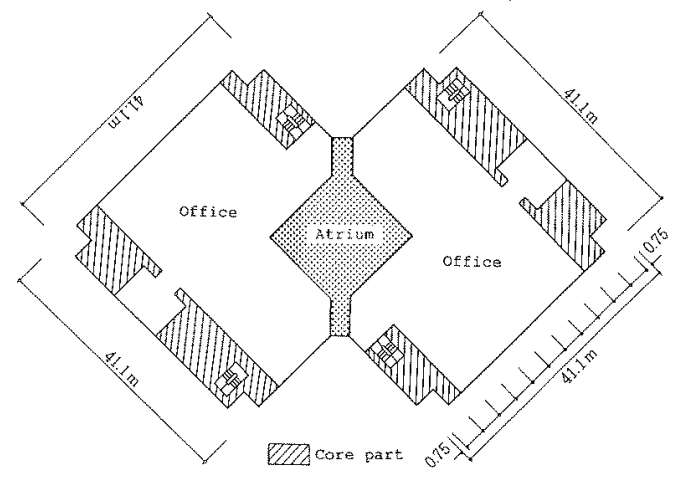

Fig.1 Typical Floor Plan of Object Atrium Building

The design of this building is characterized by natural sunitight coming in from the top and sides of the atrium for the benefit of the office spaces. Important matters for discussion were determining the fire resistance of the aluminum curtain walls and the size of the openings. 
Based on an analysis of potential fire hazards in each space in the building, it was judged that the atrium base part and its surrounding rooms were critical in terms of both fire occurrence probability and fire load. Therefore, the purpose of the research was chosen to be that of determining a fire resistance level for the atrium peripheral walls and openings which would be sufficient for office fires in the building, when air is supplied at the lower part of the atrium and smoke is discharged at the top.

Different specifications of the atrium peripheral walls and the openings were chosen to examine the following items: i) the fire behavior in the office spaces ii) the possibility of the spread of the fire to upper floors and to other atrium surfaces and iii) accumulation of smoke in the atrium. By looking at different conditions, it was decided to determine the fire resistance specifications of the atrium peripheral walls, the dimensions of the openings as well as the necessary size of the smoke discharge outlet from the atrium to the outside to meet the fire resistance requirements.

\section{PREDICTION OF FIRE BEHAVIOR IN THE OFFICE SPACES}

The single-room office space on the second floor of Building A was assumed to be a fire zone. The behavior of a fully developed fire was examined using a method developed by Kawagoe ${ }^{1}$. In this method, it was assumed that the fire in the compartment becomes either ventilation controlled or fuel controlled, which is determined by the relation between the air supply through the oepning of the compartment and the necessary air based on the fuel surface area in any fire situa$\left.\operatorname{tion}^{2}\right)$. In this study, the area of the fire zone was $932.2 \mathrm{~m}^{2}$ and the height of the floor was $4 \mathrm{~m}$.

The behavior of a fully developed fire is determined by the characteristics of the openings and the fire load. This zone has openings at the exterior walls and on the atrium peripheral walls. The dimensions of the former were fixed beforehand, from the viewpoint of overall appearance, to be $43.2 \mathrm{~m}$ in width and $1.9 \mathrm{~m}$ in height. Therefore, the discussion concentrated on how the fire behavior depends on the dimensions of the opening facing the atrium, whose width was fixed at $28.8 \mathrm{~m}$.

With regards to the fire load, it was decided to use $30 \mathrm{~kg} / \mathrm{m}^{2}$, an average value for office buildings. Since most combustibles in this case are paper documents and they tend to be piled together, the surface area per unit weight is small, and the fire load was represented by 4-cm cross-section pieces of timber from a silver fir sapwood (specific gravity $0.486 \mathrm{t} / \mathrm{m}^{3}$, moisture content $13 \%$ ) which were cross-piled in layers. The walls and the floor of this zone are made of lightweight concrete and the specifications were set at the specific gravity of $1.54 \mathrm{t} / \mathrm{m}^{3}$, the thermal conductivity of $0.644 \mathrm{~W} / \mathrm{m} \mathrm{K}$, specific heat $880 \mathrm{~J} / \mathrm{kg} \mathrm{K}$ and the moisture content 7\%. As initial conditions for calculations, temperatures inside the spaces were $15{ }^{\circ} \mathrm{C}$. It was also assumed that the glass of the outer walls and atrium walls is broken, and air can pass freely through the openings.

According to the results of a series of calculations with different oepning heights (the height of the bottom of the opening from the floor is fixed at $80 \mathrm{~cm}$ while the distance from the top to the ceiling is variable), it was concluded that the optimum height of an opening is $1.23 \mathrm{~m}$ for preventing the spread of fire to upper floors and to the opposite building, as well as preventing glass falling into the atrium. The fire behavior with this specification is shown in Figs.2 and 3 . As Fig.2 shows, it is predicted that the temeprature will rise to 1000 
${ }^{\circ} \mathrm{C} 30$ minutes after the fire starts and the fire will be extinguished within 60 minutes after ignition. Based on this prediction, it is considered that 1 hour of fire resistance capability is sufficient for the partition walls facing the atrium.

Fig. 3 shows the change in rate of heat release with time. In this figure $\mathrm{OK}$ (heat emitted by the flame from the opening), which is represented by a chain line, was used as input data for further discussion.
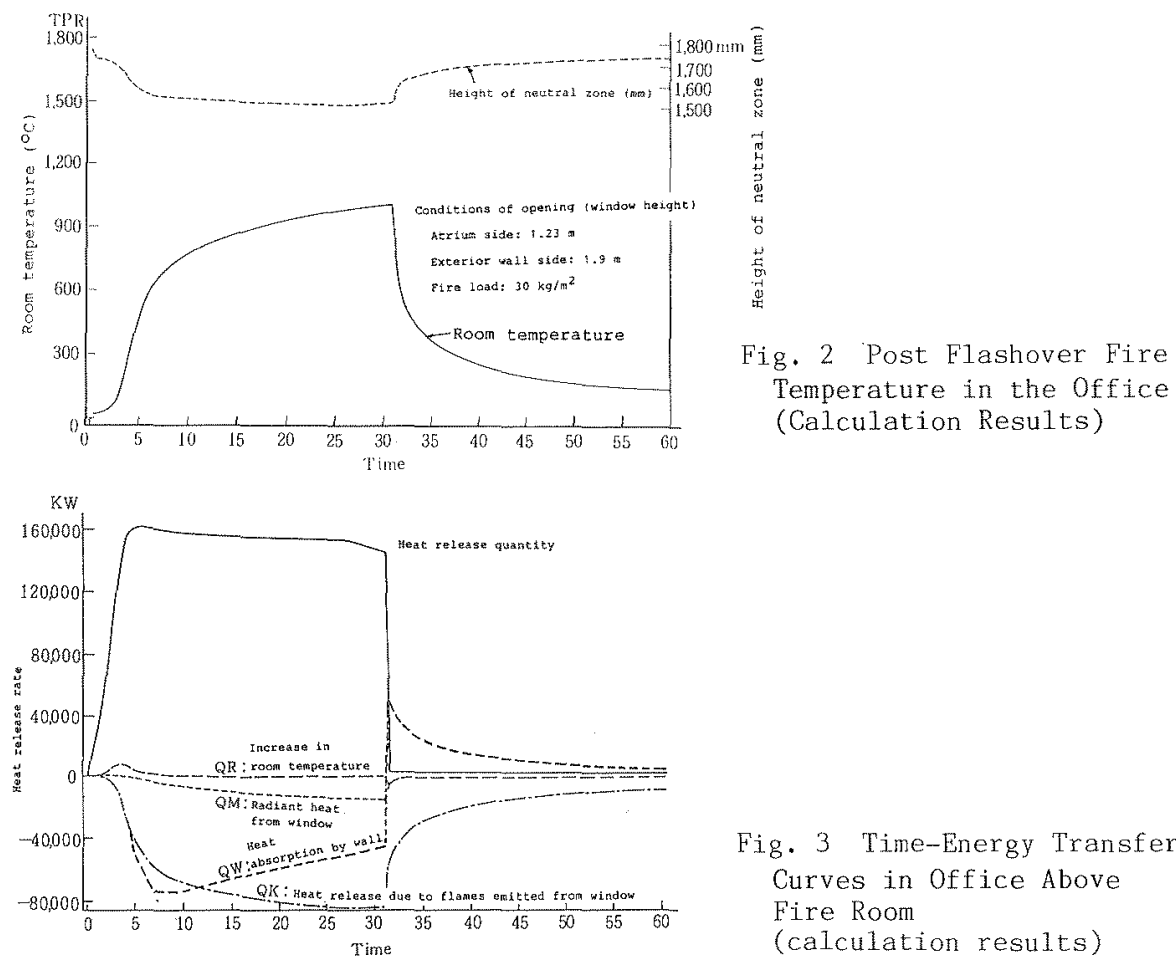

Fig. 3 Time-Energy Transfer Curves in Office Above Fire Room (calculation results)

\section{PREDICTION CONCERNING FIRE SPREAD TO UPPER FLOORS}

It is an absolute necessity that in any bulding fire be prevented from spreading upwards floor by floor. Dr. Yokoi's ${ }^{3}$ method was used in this study, and the increase in glass temeprature at the floor above the fire was investigated. Also obtained was the height of the spandrel which is required to prevent the fire from spreading towards the upper floors, prevent the falling of broken glass, and prevent the ignition of paper and wood materials behind the glass. 


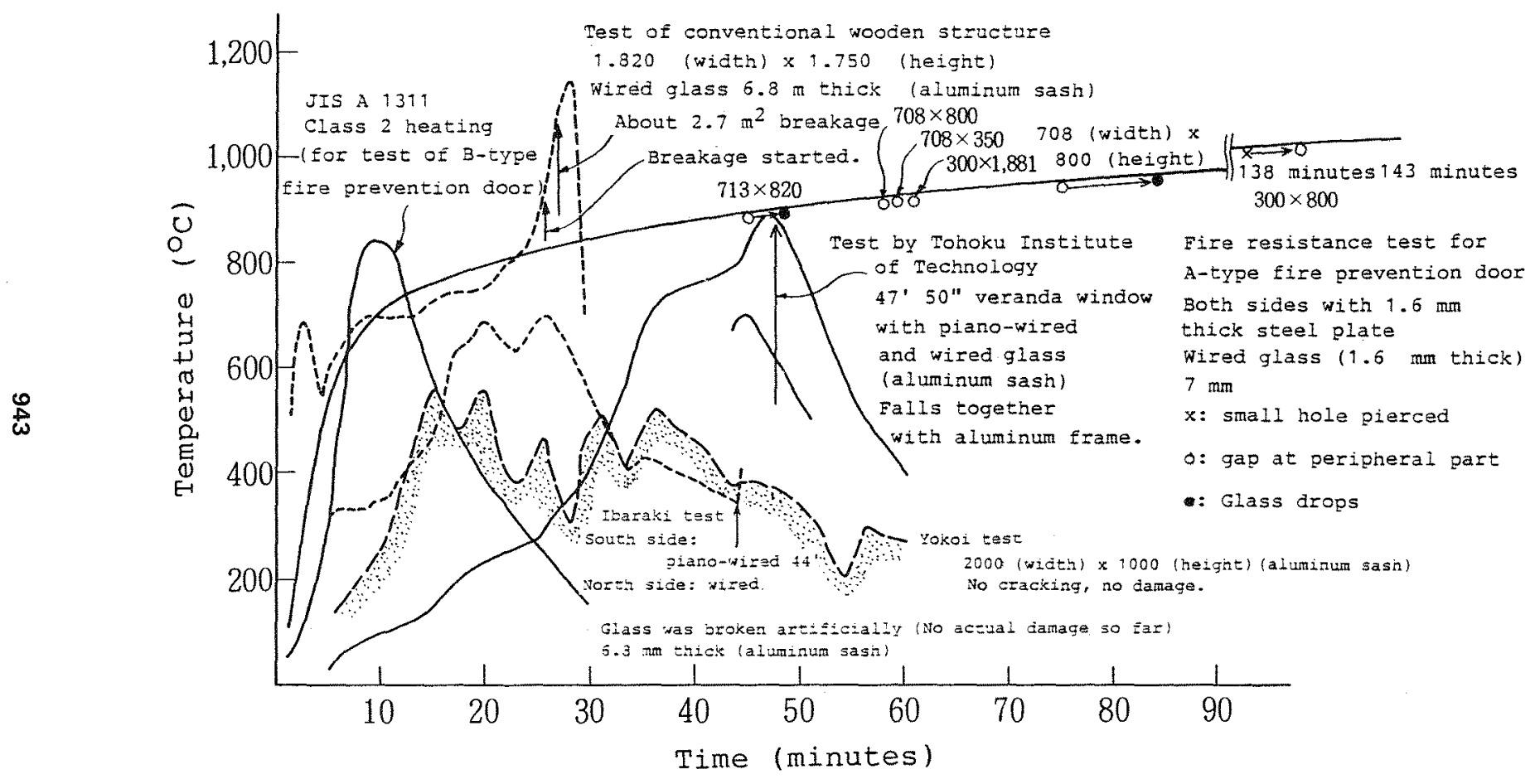

Fig. 4 Trajectory Hot Gas Emitting from a Window (Test results) 
If both the smoke discharge outlet at the top and the air inlet at the lower part of the atrium are open when a fire occurs in the office buildings, spouting flames in conditions of complete calm occur both on the outer side and the atrium side in proportion to the areas of the openings, as for ordinary buildings. Dr. Yokoi ascertained that calculations of emitted energy for a long wide horizontal opening should be corrected by $8 / 5$, at maximum, of the actual emitted energy, and that the extreme value of QK in Fig. 3 should be adopted as the heat emitted by the flame.

The results of the calculations are shown in Fig.5. It was considered that the glass surface on the top floor may face flames with a temperature of between 410 and $535^{\circ} \mathrm{C}$. In general, breakage resistance of window glass against heat varies depending on the glass dimensions, type and dimensions of the window frame and aluminum extrusion shape, etc., which make general conclusions rather difficult to determine. However, as can be seen from Fig. 44)-9), a fixed window with an aluminum sash, $1.23 \mathrm{~m}$ high, and with wired glass to prevent the falling of glass would be sufficient as a barrier to flame spread. In the following section, the possibility of the spread of fire due to heat transmission from the window surface to the inside room was studied by the same method. The results show that at the opposite side the temperature of the glass with a thickness of $6.8 \mathrm{~mm}$ would be below $120^{\circ} \mathrm{C}$.

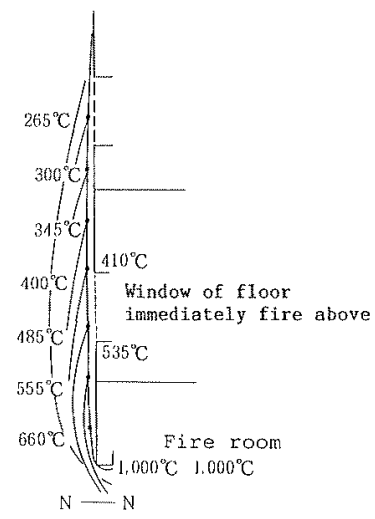

Fig. 5 Fire Resistance of Wired Glass (Calculation Results)

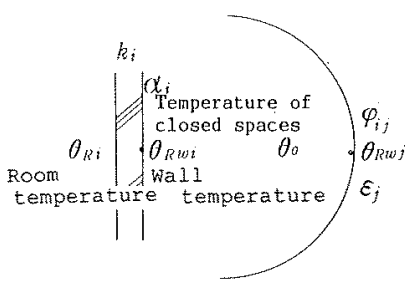

Fig. 6 Heat Radiation Model for Closed System

\section{PREDICTION OF THE POSSIBILITY OF FIRE SPREADING TO THE OPPOSITE BUILDING.}

The possibility of the fire spreading to Building $B$ on the opposite sides, due to heat transmission by radiation was discussed for the case of a fire occurring on a floor midway up in Building $A$. The conditions are the same as those mentioned above. An opening on Building $A$ is broken, and flames spread along the wall of Building $A$. (The flame height is $7.4 \mathrm{~m}$, coming out of an area $28.8 \mathrm{~m}$ wide $\mathrm{x} 13.57 \mathrm{~m}$ high, as shown in Fig. 7.) 
Concerning the transmission of radiant heat between the limited plane surfaces, the following assumptions were made: i) the heat capacity of the wall is small, so the time lag is ignored; ii) radiation strikes only the wall facing the fire room; and iii) gas radiation in a closed space can be neglected. Based on these assumptions, the heat balance on the surface of the wall structure concerning the model in Fig. 6 can be expressed as follows:

$$
\begin{aligned}
Q_{i}=k_{i}\left(\theta_{R i}-\theta_{R w i}\right)+\alpha_{i}\left(\theta_{o}-\theta_{R w i}\right) \\
+C_{b} \varepsilon_{i}\left\{\sum_{j} \varepsilon_{i j}\left(\frac{{ }_{R} w i}{100}\right)^{4}-\left(\frac{T_{R w i}}{100}\right)^{4}\right\}
\end{aligned}
$$

where

$$
\begin{array}{ll}
k i: & \begin{array}{l}
\text { total net transmission coefficient for the } \\
\text { peripheral wall }
\end{array} \\
\alpha i: & \begin{array}{l}
\text { heat-transfer coefficient through the } \\
\text { peripheral wall }
\end{array} \\
\mathrm{Cb}: \quad \text { Stephan-Boltzmann constant } \\
\varepsilon_{i}, \varepsilon_{j}: \quad \text { emissivity } \\
\psi_{i j}: \quad \text { shape factor between planes }
\end{array}
$$

For calculations of the shape factor, the wall surface is divided into the glass part and the aluminum curtain wall part, as shown in Fig.7. The glass surface facing the floor of the fire was again divided into 10 equal parts. The values used for the calculations were:

$$
\begin{aligned}
& \text { For glass } \varepsilon=0.6 \quad \lambda=0.8 \mathrm{~W} / \mathrm{m}^{*} \mathrm{~K} \quad \mathrm{~d}=6.8 \mathrm{~mm} \\
& \text { For aluminum } \varepsilon=0.6 \quad \lambda=217.4 \mathrm{~W} / \mathrm{m} \cdot \mathrm{K} d=1.0 \mathrm{~mm} \\
& \text { For fire resistant pane1 with rock wool backing } \\
& \qquad \lambda=0.06 \mathrm{~W} / \mathrm{m}^{*} \mathrm{~K} \quad \mathrm{~d}=25 \mathrm{~mm}
\end{aligned}
$$

$25{ }^{\circ} \mathrm{C}$ was taken as the temperature inside the atrium and in the rooms not facing the fire. The heat-transfer coefficient in the room and the convective heat-transfer coefficient in the atrium were taken as $11.63 \mathrm{~W} / \mathrm{m}^{2} \cdot \mathrm{K}$ and $23.26 \mathrm{~W} / \mathrm{m}^{2} \cdot \mathrm{K}$, respectively. The results of the above equation are shown in Fig.7. According to the figure, the maximum temperature on the opposite side of the atrium is $210^{\circ} \mathrm{C}$, which suggests far less risk of fire spreading than the $410{ }^{\circ} \mathrm{C}$ which was obtained in the calculations concerning possible flame spread to higher floors. 


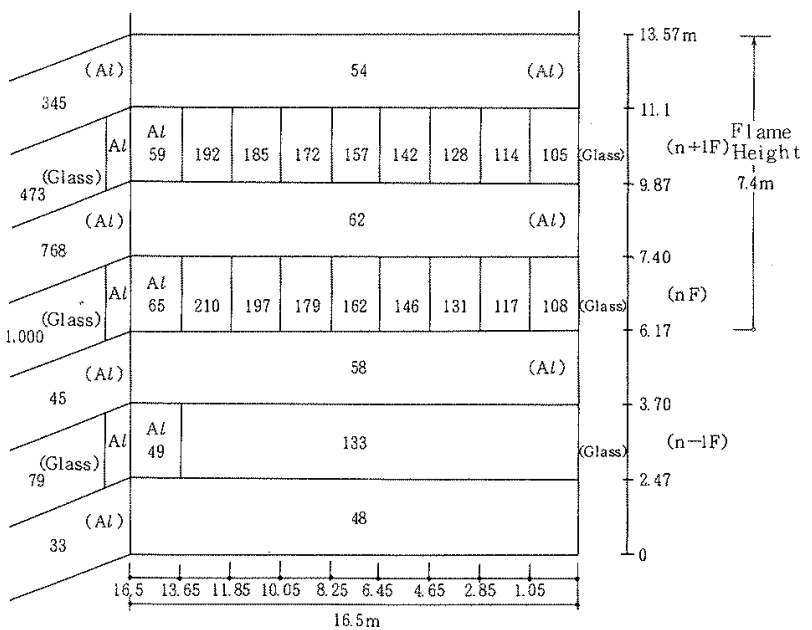

Fig. 7 Temperature Rise in Atrium Wall Surfaces (Calculation Results)

\section{PREDICTION OF ACCUMULATING A SMOKE LAYER IN THE ATRIUM}

Improving on Tanaka's ${ }^{10}$ ) two layer zone model, the effect of the conditions of the top smoke discharge outlet on the behavior of the smoke layer that accumulates in the atrium was investigated. In one case the outlet was left open, while in the other, it was closed. For the atrium conditions to be similar to those on the outside, the systems opened the top smoke discharge outlet and the air supply inlet below immediately after detection of a fire, so that the flames emitted from a fire room did not flow into the atrium side only.

Calculations were performed under the assumptions of no wind and the temperatures inside and outside the room being $25^{\circ} \mathrm{C}$. Two cases were investigated: one with the smoke discharge outlet at the top of the atrium open and the other with it closed. From the results of the calculation with different effective areas of the top smoke discharge outlet, $\left(0,5,10,20\right.$ and $\left.40 \mathrm{~m}^{2}\right)$. it was concluded that the area should be at least $20 \mathrm{~m}^{2}$. Thus in this study, the cases of 0 $\mathrm{m}^{2}$ and $20 \mathrm{~m}^{2}$ were taken. Also, the area of the opening facing the atrium was taken as the area of the fire source $(28.8 \mathrm{~m} \times 1.23 \mathrm{~m}=$ $35.424 \mathrm{~m}^{2}$ ). The size of the lower air supply inlet was assumed to be the same. It was also assumed that the wall of the atrium was totally covered by wired glass of a $6.8 \mathrm{~mm}$ thickness (total heat transmission coefficient $12.38 \mathrm{~W} / \mathrm{m}^{2} \cdot \mathrm{K}$ ).

The results are shown in Fig.8. If the top smoke discharge outlet is closed, the smoke drops to the neutral zone of the fire f1oor 6.5 minutes after the opening on the atrium side breaks. If the smoke discharge outlet is open, the effect is for a smoke layer to be formed near the top floor only. On the other hand, the temperature of the smoke layer tends to rise as time passes, and 200 to $300{ }^{\circ} \mathrm{C}$ is reached within 15 minutes. 


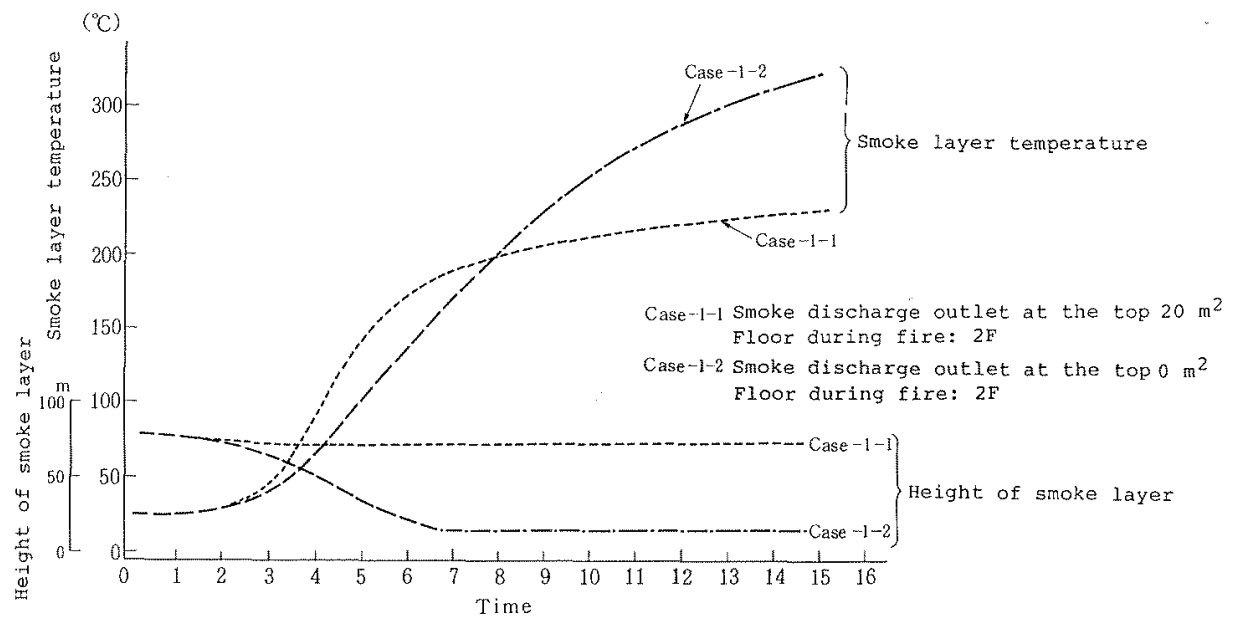

Fig. 8 Smoke Accumulation Speed in the Atrium (Calculation Resu1ts)

Judging from the above results, an efficient smoke discharge system is considered one of most important requirements for atrium architecture and such a system should have a reliable way to open a smoke discharge outlet and an air supply inlet. It is also advisable that wired glass should be used to prevent window glass from breaking, even when exposed to very high temperatures.

\section{CONCLUSION}

It was confirmed that safety in a building during a fire can be secured, without compromising rationality or reducing freedom of design, by means of systematically applying the above mentioned requirements. Further research is planned to improve the accuracy of the various prediction methods and to make their application readily available to designers. For example, this could be done by using personal computer programs or putting figures into the form of diagrams.

\section{REFERENCE}

$1 \quad$ K. Kawagoe and T. Sekine, Estimation of Fire Temperature-Time Curve in Rooms. Occasional Report No.11, Building Research Institute, Tokyo (1963) - K. Kawagoe, Estimation of Fire TemperatureTime Curve in Rooms. Research Paper No.29, Building Research Institute, Tokyo (1967).

2 H. Sato, Study on a Tota1 Fire Safety System (Part 4), Annual Report of Kajima Institute of Construction Technology KAJIMA CORPORATTON, VOI.33 (1986) 
3 S. Yokoi, Temperature Distribution of llot Air Current Issued from A Window of A Fire Resistive Construction in Fire, Bul1 of the Fire Prevention Society of Japan, Vol.7, No.2 (March, 1958)

S. Yokoi, Experimental Fire in a Ful1-scale Reinforced Concrete Room, Bul1 of The Fire Prevention Society of Japan Vol.9, No.I (Oct., 1959)

4 Saka, Fire Resistance Tests on A-type Fire Doors (Parts 1 and 2), GBRC Nos. 17 and 18,1980 and 1981 .

5 Saga et al., Full-Scale Fire Test on PC Structure House, Summaries of Technical Papers from Annual Meeting, Architectural Institute of Japan, 1978

6 Sugawara et a1., Fire Test on Conventional Wooden Structure with a Single Room Model (Parts 1 and 2), Summaries of Technical papers of Annual Meeting, Architectural Institute of Japan, 1981

7 Oguni et al., Ful1-Size Fire Tests on Reinforced Concrete Apartment Housing (I) and (II), Fire Vo1.33, No.6 and Vol.34, No.1, 1983 and 1984

8 S. Yokoi, Report on Fire Tests for Fire Resistant Construction, Collection of Technical Papers, Japanese Association of Fire Science and Engineering, Vo1.9, No.1, 1959

9 Hamada et al., Study of Window Glass for Fire Prevention, Collection of Technical Papers, Japanese Association of Fire Science and Engineering, Vol.7, No.2, 1958

10 T. Tanaka, A Model of Fire Spread in Small Scale Buildings. Research Paper No.84, Building Research Institute, Tokyo (1980). T. Tanaka, A Mode1 of Multiroom Fire Spread, NBSIR 83-2718 (August 1983)

\section{ACKNOWLEDGEMENT}

I would like to express my gratitude to Nihon Sekkeijimusyo Co., Ltd. for giving me the opportunity to make this presentation. 